\title{
The role of secondary hyperparathyroidism in left ventricular hypertrophy of patients under chronic hemodialysis
}

R.B. Randon ${ }^{1}$, L.E. Rohde²,

L. Comerlato ${ }^{3}$, J.P. Ribeiro ${ }^{2,4}$ and R.C. Manfro ${ }^{1,3,4}$
Correspondence

R.C. Manfro

Serviço de Nefrologia

Hospital de Clínicas de Porto Alegre

Rua Ramiro Barcelos 2350, Sala 2030

90035-903 Porto Alegre, RS

Brasil

Fax: +55-51-2101-8001

E-mail: rmanfro@hcpa.ufrgs.br

Research partially supported by the Research Incentive Fund (FIPE),

Hospital de Clínicas de Porto Alegre.

L.E. Rohde is a CNPq investigator.

The present address of R.B. Randon is Departamento de Pediatria e Divisão de Nefrologia, Universidade de Caxias do Sul, Caxias do Sul, RS, Brasil.

Received September 22, 2004 Accepted June 3, 2005 .....................
1Programa de Pós-Graduação em Nefrologia, ${ }^{2}$ Serviço de Cardiologia, ${ }^{3}$ Serviço de Nefrologia, Hospital de Clínicas de Porto Alegre, ${ }^{4}$ Departamento de Medicina Interna, Faculdade de Medicina, Universidade Federal do Rio Grande do Sul, Porto Alegre, RS, Brasil

\begin{abstract}
End-stage renal disease (ESRD) patients frequently develop structural cardiac abnormalities, particularly left ventricular hypertrophy (LVH). The mechanisms involved in these processes are not completely understood. In the present study, we evaluated a possible association between parathyroid hormone (PTH) levels and left ventricular mass (LVM) in patients with ESRD. Stable uremic patients on intermittent hemodialysis treatment were evaluated by standard two-dimensional echocardiography and their sera were analyzed for intact PTH. Fortyone patients (mean age 45 years, range 18 to 61 years), $61 \%$ males, who had been on hemodialysis for 3 to 186 months, were evaluated. Patients were stratified into 3 groups according to serum PTH: low levels $(<100 \mathrm{pg} / \mathrm{ml}$; group I $=10$ patients), intermediate levels (100 to $280 \mathrm{pg} / \mathrm{ml}$; group II $=10$ patients $)$ and high levels $(>280 \mathrm{pg} / \mathrm{ml}$; group $\mathrm{III}=21$ patients). A positive statistically significant association between LVM index and PTH was identified $(r=0.34 ; \mathrm{P}=0.03$, Pearson's correlation coefficient) in the sample as a whole. In subgroup analyses, we did not observe significant associations in the low and intermediate PTH groups; nevertheless, PTH and LVM index were correlated in patients with high PTH levels $(r=0.62 ; \mathrm{P}=0.003)$. LVM index was also inversely associated with hemoglobin $(r=-0.34$; $\mathrm{P}=0.03$ ). In multivariate analysis, after adjustment for age, hemoglobin, body mass index, and blood pressure, the only independent predictor of LVM index was PTH level. Therefore, PTH is an independent predictor of LVH in patients undergoing chronic hemodialysis. Secondary hyperparathyroidism may contribute to the elevated cardiovascular morbidity associated with LVH in ESRD.
\end{abstract}

Key words

- End-stage renal failure

- Parathyroid hormone

- Echocardiography

- Left ventricular hypertrophy

\section{Introduction}

End-stage renal disease (ESRD) has been associated with changes in the structure and function of the myocardium (1). A significant percentage of patients who start dialysis treatment have cardiac abnormalities, particularly left ventricular hypertrophy $(\mathrm{LVH})$ (2). Likewise, approximately $70 \%$ of the patients under chronic hemodialysis treatment present LVH $(2,3)$. Different conditions have been implicated in the pathogen- 
esis of ESRD-related LVH, such as hypertension, chronic anemia, arteriovenous fistulas, concurrent ischemic heart disease, and hypoalbuminemia. These factors have independent effects, which possibly act synergistically leading to LVH and its related morbidity and mortality $(4,5)$.

Recently, parathyroid hormone (PTH) has been identified as an important cardiotoxin in ESRD. Previous studies have supported the view that high PTH serum levels in uremic patients may cause deleterious effects in myocardium metabolism and function (4). The association between PTH levels and LVH has been reported by some investigators, with inconsistent results (6-9). The present study was therefore conducted to evaluate the independent association between intact PTH levels and the presence of $\mathrm{LVH}$ in end-stage stable uremic patients under chronic hemodialysis, in whom other known risk factors for $\mathrm{LVH}$ were not present.

\section{Material and Methods}

\section{Subjects}

Forty-one adult ESRD patients receiving renal replacement therapy with hemodialysis for at least three months were included. Patients with diabetes mellitus, severe anemia (hematocrit $<20 \%$ ), body mass index (BMI) $<15 \mathrm{~kg} / \mathrm{m}^{2}$, coronary artery disease, uncontrolled hypertension, primary or secondary cardiomyopathies, known valvular heart disease or pericarditis, a history of heavy alcohol consumption associated with altered liver function tests, parathyroidectomy, and connective tissue disease were excluded. All patients who agreed to participate in this protocol signed an informed consent document. The research protocol was approved regarding its ethical and methodological aspects by the Ethics Committee in Research Procedures of Hospital de Clínicas de Porto Alegre, Universidade Fe- deral do Rio Grande do Sul Medical School, accredited by the Brazilian National Research Committee, and registered at the Office for Human Research Protection (OHRPUSDHHS) as an Institutional Reviewing Bureau (IRB 00000921).

\section{Two-dimensional echocardiography}

Color Doppler echocardiograms were performed by one of the investigators (LER) using the ATL HDI 5000 (ATL Ultrasound, Bothel, WA, USA) ultrasound equipment with a 2.5-3.5 MHz transducer and harmonic imaging. Echocardiograms were performed with the patients within a maximum of $3 \%$ above the estimated dry weight (weight when normotensive and free of edema). The echocardiographic parameters studied in this protocol were evaluated according to the recommendations of the American Society of Echocardiography. For each measurement, 3-5 consecutive cardiac cycles were analyzed and the average was computed. Left ventricular mass (LVM) was calculated according to the modified cube formula proposed by Devereux et al. (10). LVM index was calculated by dividing LVM by body surface. An LVM index above $100 \mathrm{~g} / \mathrm{m}^{2}$ for women and above $131 \mathrm{~g} / \mathrm{m}^{2}$ for men was considered to indicate LVH (11).

\section{Blood analysis}

Plasma PTH measurements were carried out by a radioimmunoassay technique measuring intact PTH (Immunolite 2000, Diagnostic Products Corporation, Los Angeles, CA, USA). Intra-assay and interassay coefficients of variation for this test are 5.7 and 8.8 , respectively. The patients were classified into three groups according to their plasma PTH levels: group I, PTH $<100$ pg/ $\mathrm{ml}$ (low PTH levels, $\mathrm{N}=10$ ); group II, PTH between 100 to $280 \mathrm{pg} / \mathrm{ml}$ (intermediate PTH levels, $\mathrm{N}=10$ ), and group III, PTH $>280 \mathrm{pg}$ / $\mathrm{ml}$ (high PTH levels, $\mathrm{N}=21$ ). 
Other laboratory tests were carried out by standardized clinical laboratory methods and included total alkaline phosphatases, bone-fraction alkaline phosphatase, total calcium, phosphorous, pre- and post-dialysis urea, creatinine, alanine aminotransferase, aspartate aminotransferase, albumin, total cholesterol, triglycerides, hematocrit, hemoglobin, serum iron, and serum aluminum. Bone-fraction alkaline phosphatase was measured by the thermal inactive enzyme method (12). Averaged 12-month data of urea fractional clearance and urea reduction rate were used for the biochemical evaluation of dialysis adequacy.

\section{Other measurements}

Blood pressure was evaluated by averaging the measurements obtained before hemodialysis over a period of 6 months preceding the echocardiographic examination. BMI was calculated using the formula: BMI $=$ weight $/$ height $^{2}\left(\mathrm{~kg} / \mathrm{m}^{2}\right)$.

\section{Statistical analysis}

Data are reported as means $\pm \mathrm{SD}$ or as percentages. Differences in echocardiographic, clinical, and laboratory variables between dif- ferent PTH groups were evaluated by analysis of variance. The Tukey test was used for multiple comparisons. The association between PTH and LVM index and the other variables was evaluated by Pearson's correlation coefficient. Multiple linear regression analysis was used to evaluate the relation between PTH and LVM index, controlling for variables that may potentially influence LVM index. A two-tailed $\mathrm{P}$ value $<0.05$ was considered to be statistically significant. Statistical analysis was carried out using the SPSS Program, version 8.0.

\section{Results}

The demographic and anthropometric characteristics of the patients are presented in Table 1. Causes of renal failure were: a) hypertensive nephrosclerosis in $10(24 \%)$ patients, b) polycystic kidney disease in 8 (20\%), c) glomerular diseases in $5(12 \%)$, d) obstructive uropathy in $4(10 \%)$, e) Alport syndrome, chronic pyelonephritis, U-shaped kidneys and HIV nephropathy in 1 (2\%) patient each, and e) undetermined etiology in $11(24 \%)$ patients.

Laboratory variables are shown in Table 2 for the patients as a whole and stratified by PTH groups. Alkaline phosphatase levels were significantly higher in the high PTH

\begin{tabular}{|c|c|c|c|c|}
\hline Parameters & $\begin{array}{l}\text { Overall group } \\
\qquad(\mathrm{N}=41)\end{array}$ & $\begin{array}{l}\text { Group I } \\
(N=10)\end{array}$ & $\begin{array}{l}\text { Group II } \\
(N=10)\end{array}$ & $\begin{array}{l}\text { Group III } \\
(\mathrm{N}=21)\end{array}$ \\
\hline Age (years) & $45 \pm 11(18-61)$ & $48 \pm 13$ & $48 \pm 10$ & $42 \pm 11$ \\
\hline Weight $(\mathrm{kg})$ & $66 \pm 17(38-114)$ & $64 \pm 18$ & $76 \pm 20$ & $62 \pm 13$ \\
\hline Height $(\mathrm{cm})$ & $166 \pm 11(147-193)$ & $167 \pm 12$ & $171 \pm 12$ & $163 \pm 8$ \\
\hline BMI $\left(\mathrm{kg} / \mathrm{m}^{2}\right)$ & $23.7 \pm 4.1(16.2-34.4)$ & $23.2 \pm 4.5$ & $25.5 \pm 3.9$ & $23 \pm 3.8$ \\
\hline Time until echo (months) & $58 \pm 42(3-186)$ & $58 \pm 44$ & $55 \pm 36$ & $59 \pm 45$ \\
\hline $\mathrm{SBP}(\mathrm{mmHg})$ & $138 \pm 17(100-174)$ & $137 \pm 16$ & $149 \pm 16$ & $134 \pm 16$ \\
\hline $\mathrm{DBP}(\mathrm{mmHg})$ & $81 \pm 10(59-103)$ & $80 \pm 10$ & $86 \pm 11$ & $80 \pm 10$ \\
\hline Male gender (yes/no) & $26 / 15$ & $7 / 3$ & $7 / 3$ & $12 / 9$ \\
\hline White/not white & $15 / 26$ & $7 / 3$ & $8 / 2$ & $10 / 11$ \\
\hline Anti-hypertensive medications (yes/no) & $14 / 27$ & $1 / 9$ & $6 / 4$ & $7 / 14$ \\
\hline
\end{tabular}

Data are reported as means \pm SD and (range) unless otherwise indicated. Groups I, II, III = low, intermediate and high serum PTH levels, respectively. BMI = body mass index; time until echo $=$ hemodialysis time until echocardiography; SBP and DBP = systolic and diastolic blood pressure (6-month average of the pre-dialysis readings). There were no significant differences between groups (ANOVA). 
group compared to the low PTH group $(\mathrm{P}<$ 0.05 ) and a similar trend was observed for bone-specific alkaline phosphatase $(\mathrm{P}=$ 0.06). Serum total calcium levels were significantly lower in the high PTH group, while serum phosphorous, calcium-phosphorous product, triglycerides, total cholesterol, and albumin were higher in the intermediate PTH group. Other laboratory variables did not differ among groups (Table 2).

Echocardiographic variables were not significantly different among groups. Table 3 shows the echocardiographic data for the patients as a whole and according to PTH levels. Overall, left ventricle dimensions and systolic function were within normal values, except for a slightly increased diastolic septal wall thickness.

Although dialysis time did not differ among groups (Table 1), a significant correlation between PTH level and hemodialysis time was observed in all patients $(\mathrm{P}=0.02)$, and with a higher level of association in subgroup analysis $(\mathrm{P}=0.002$ for the high PTH group). Likewise, significant correlations were observed between PTH and total alkaline phosphatases $(\mathrm{P}=0.001)$ and bonefraction alkaline phosphatase $(\mathrm{P}=0.001)$ in all patients and also in the high PTH group $(\mathrm{P}=0.001$; Table 4). As shown in Figure 1,

Table 2. Laboratory measurements.

\begin{tabular}{lccccl}
\hline Parameters & $\begin{array}{c}\text { Overall group } \\
(\mathrm{N}=41)\end{array}$ & $\begin{array}{c}\text { Group I } \\
(\mathrm{N}=10)\end{array}$ & $\begin{array}{c}\text { Group II } \\
(\mathrm{N}=10)\end{array}$ & $\begin{array}{c}\text { Group III } \\
(\mathrm{N}=21)\end{array}$ & P value \\
\hline PTH $(\mathrm{pg} / \mathrm{ml})$ & $381 \pm 412$ & $28 \pm 23$ & $148 \pm 54$ & $661 \pm 408$ & 0.0001 \\
AP $(\mathrm{U} / \mathrm{l})$ & $332 \pm 275$ & $163 \pm 84$ & $317 \pm 428$ & $420 \pm 206$ & $0.046^{*}$ \\
Bone-AP (U/l) & $286 \pm 226$ & $166 \pm 122$ & $247 \pm 285$ & $361 \pm 211$ & 0.06 \\
Total calcium (mg/dl) & $9.1 \pm 1.2$ & $9.6 \pm 0.8$ & $9.6 \pm 1.4$ & $8.7 \pm 1.0$ & $0.04^{*}$ \\
Phosphorous (mg/dl) & $5.8 \pm 1.6$ & $4.8 \pm 1.7$ & $6.6 \pm 1.6$ & $5.8 \pm 1.3$ & $0.04^{* *}$ \\
Ca $\times$ P $(\mathrm{mg} / \mathrm{dl}))^{2}$ & $53 \pm 17$ & $48 \pm 18$ & $63 \pm 20$ & $50 \pm 14$ & 0.08 \\
Albumin $(\mathrm{g} / \mathrm{dl})$ & $4.0 \pm 0.3$ & $3.8 \pm 0.4$ & $4.1 \pm 0.3$ & $4.0 \pm 0.3$ & $0.04^{*}$ \\
Total cholesterol $(\mathrm{mg} / \mathrm{dl})$ & $166 \pm 41$ & $156 \pm 30$ & $190 \pm 56$ & $160 \pm 33$ & 0.09 \\
Triglycerides $(\mathrm{mg} / \mathrm{dl})$ & $183 \pm 117$ & $147 \pm 47$ & $305 \pm 175$ & $144 \pm 54$ & $0.003^{* * *}$ \\
Serum aluminum $(\mu \mathrm{gg} / \mathrm{l})$ & $2.7 \pm 1.7$ & $3.2 \pm 1.8$ & $3.2 \pm 2.6$ & $2.2 \pm 0.9$ & 0.23 \\
Kt/V & $1.3 \pm 0.3$ & $1.4 \pm 0.3$ & $1.2 \pm 0.2$ & $1.2 \pm 0.2$ & 0.19 \\
URR $(\%)$ & $64.5 \pm 7.8$ & $68.6 \pm 9.9$ & $60.9 \pm 7.3$ & $64.6 \pm 6.7$ & 0.12 \\
Hemoglobin $(\mathrm{g} / \mathrm{dl})$ & $9.7 \pm 1.6$ & $9.6 \pm 2.0$ & $9.6 \pm 1.5$ & $9.8 \pm 1.4$ & 0.89 \\
Serum iron $(\mu \mathrm{g} \%)$ & $63 \pm 20$ & $66 \pm 26$ & $67 \pm 20$ & $62 \pm 17$ & 0.75 \\
\hline
\end{tabular}

Data are reported as means \pm SD. Groups I, II, III = low, intermediate and high serum PTH levels, respectively. $\mathrm{PTH}=$ parathyroid hormone; $\mathrm{AP}=$ total alkaline phosphatases; Bone-AP $=$ bone fraction of alkaline phosphatase; $\mathrm{Ca} \times \mathrm{P}=$ calcium $\times$ phosphorous product; $\mathrm{Kt} / \mathrm{V}=$ urea fractional clearance; URR = urea reduction rate. ANOVA *between groups I and III; **between groups I and II; ***between groups I and II, and groups II and III.

Table 3. Echocardiographic parameters.

\begin{tabular}{lcccc}
\hline Parameters & $\begin{array}{c}\text { All patients } \\
(\mathrm{N}=41)\end{array}$ & $\begin{array}{c}\text { Group I } \\
(\mathrm{N}=10)\end{array}$ & $\begin{array}{c}\text { Group II } \\
(\mathrm{N}=10)\end{array}$ & $\begin{array}{c}\text { Group III } \\
(\mathrm{N}=21)\end{array}$ \\
\hline Diastolic septal thickness wall $(\mathrm{cm})$ & $1.2 \pm 0.2$ & $1.3 \pm 0.3$ & $1.2 \pm 0.2$ & $1.2 \pm 0.2$ \\
Diastolic LV diameter $(\mathrm{cm})$ & $4.8 \pm 0.7$ & $4.7 \pm 0.8$ & $5.2 \pm 0.5$ & $4.7 \pm 0.8$ \\
Diastolic posterior wall thickness $(\mathrm{cm})$ & $1.0 \pm 0.2$ & $1.0 \pm 0.1$ & $1.1 \pm 0.1$ & $1.0 \pm 0.2$ \\
Systolic LV diameter $(\mathrm{cm})$ & $3.0 \pm 0.6$ & $3.0 \pm 0.8$ & $3.2 \pm 0.5$ & $2.9 \pm 0.5$ \\
LVM $(\mathrm{g})$ & $204 \pm 68$ & $194 \pm 50$ & $231 \pm 45$ & $196 \pm 81$ \\
LVM index $\left(\mathrm{g} / \mathrm{m}^{2}\right)$ & $119 \pm 41$ & $117 \pm 39$ & $124 \pm 29$ & $118 \pm 48$ \\
LV ejection fraction (\%) & $68 \pm 9$ & $68 \pm 10$ & $68 \pm 7$ & $68 \pm 10$ \\
\hline
\end{tabular}

Data are reported as means \pm SD. Groups I, II, III $=$ low, intermediate and high serum PTH levels, respectively. $L V=$ left ventricle; LVM = left ventricular mass. There were no significant differences between groups (ANOVA). 
a significant correlation between PTH and LVM index was observed in all patients $(\mathrm{r}=$ $0.34 ; \mathrm{P}=0.03)$. The correlation was more prominent in the group of patients who presented the most pronounced degree of hyperparathyroidism (high PTH group; $r=0.62$; $\mathrm{P}=0.003$ ).

No significant correlations were observed between LVM index and anthropometric or clinical variables. However, a negative correlation was observed between LVM index and hemoglobin levels $(r=-0.34 ; \mathrm{P}=0.03)$.
Trends were also noted for associations between LVM index and alkaline phosphatases $(r=0.27 ; \mathrm{P}=0.08)$.

Multivariate analysis was performed including age, BMI, systolic blood pressure, hemoglobin, and PTH as independent variables and LVM index as dependent variable. Models were created for all 41 patients (model 1), aggregating the low and intermediate PTH groups (model 2) and in analyses restricted to the high PTH group (model 3). In this analysis (Table 5), LVM index was significantly and

Table 4. Person's correlation coefficients between parathyroid hormone and clinical parameters.

\begin{tabular}{|c|c|c|c|c|c|c|c|c|}
\hline \multirow[t]{2}{*}{ Parameters } & \multicolumn{2}{|c|}{$\begin{array}{l}\text { All patients } \\
\quad(\mathrm{N}=41)\end{array}$} & \multicolumn{2}{|c|}{$\begin{array}{l}\text { Group I } \\
(N=10)\end{array}$} & \multicolumn{2}{|c|}{$\begin{array}{l}\text { Group II } \\
(N=10)\end{array}$} & \multicolumn{2}{|c|}{$\begin{array}{l}\text { Group III } \\
(\mathrm{N}=21)\end{array}$} \\
\hline & $r$ & $\mathrm{P}$ & $r$ & $\mathrm{P}$ & $r$ & $P$ & $r$ & $P$ \\
\hline Time until echo & 0.36 & 0.02 & -0.06 & 0.87 & 0.14 & 0.69 & 0.63 & 0.002 \\
\hline $\mathrm{AP}(\mathrm{U} / \mathrm{I})$ & 0.55 & 0.001 & -0.20 & 0.58 & 0.08 & 0.82 & 0.72 & 0.001 \\
\hline Bone-AP (U/I) & 0.58 & 0.001 & -0.16 & 0.66 & 0.07 & 0.85 & 0.69 & 0.001 \\
\hline
\end{tabular}

Groups I, II, III = low, intermediate and high serum PTH levels, respectively. Time until echo = hemodialysis time until echocardiography; $\mathrm{AP}=$ alkaline phosphatase.

Table 5. Clinical predictors of left ventricular mass index in multiple regression analysis.

\begin{tabular}{|c|c|c|c|c|c|c|}
\hline \multirow[t]{2}{*}{ Variables } & \multicolumn{2}{|c|}{$\begin{array}{l}\text { Overall group } \\
\quad(N=41)\end{array}$} & \multicolumn{2}{|c|}{$\begin{array}{c}\text { Group I + Group II } \\
(N=20)\end{array}$} & \multicolumn{2}{|c|}{$\begin{array}{l}\text { Group III } \\
(\mathrm{N}=21)\end{array}$} \\
\hline & B & $\mathrm{P}$ value & B & $\mathrm{P}$ value & B & $\mathrm{P}$ value \\
\hline PTH & 0.03 & 0.02 & 0.84 & 0.44 & 0.07 & 0.01 \\
\hline Hemoglobin & -6.51 & 0.11 & -6.18 & 0.18 & -2.78 & 0.71 \\
\hline SBP & 0.34 & 0.35 & -0.35 & 0.45 & 0.70 & 0.27 \\
\hline Age & 1.08 & 0.10 & 1.04 & 0.22 & 0.72 & 0.48 \\
\hline \multirow[t]{2}{*}{ BMI } & -3.3 & 0.08 & -4.21 & 0.09 & -3.09 & 0.29 \\
\hline & \multicolumn{2}{|c|}{$R^{2}: 0.31$} & \multicolumn{2}{|c|}{$R^{2}: 0.38$} & \multicolumn{2}{|c|}{$\mathrm{R}^{2}: 0.47$} \\
\hline
\end{tabular}

Groups I, II, III = low, intermediate and high serum PTH levels, respectively. $B=B$ coefficient; PTH $=$ parathyroid hormone; SBP = systolic blood pressure; $\mathrm{BMI}=$ body mass index.

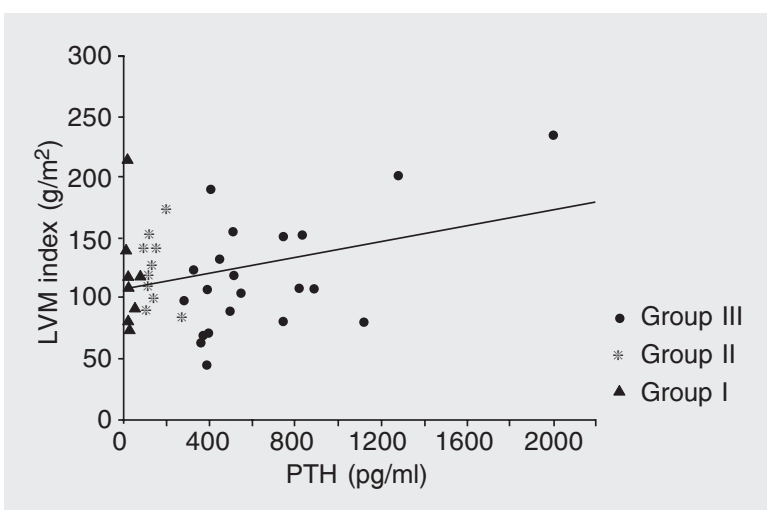

Figure 1. Dispersion diagram demonstrating the correlation between PTH levels and LVM index for all patients and for the patients divided into groups according to PTH levels. Groups I, II, III = low, intermediate and high serum PTH levels, respectively. LVM = left ventricular mass; $\mathrm{PTH}=$ parathyroid hormone. $r=0.34(P=0.03)$ for all patients and $r=0.62(P=$ 0.003 ) for high PTH group (Pearson's correlation coefficient). 
independently associated with PTH, both in model $1(\mathrm{P}=0.02)$ and model $3(\mathrm{P}=0.01)$.

\section{Discussion}

Several factors contribute to the development of LVH in patients on intermittent hemodialysis treatment, including chronic hypervolemic state, anemia, elevated blood pressure, and arteriovenous fistula (3). It has been suggested that secondary hyperparathyroidism may also play a role in the cardiovascular disease of end-stage uremia $(2,7)$, although previous studies evaluating the role of PTH in LVH in ESRD patients have led to contradictory results (6-9).

In the present study, a well-selected sample of patients was examined. Our data indicate that $\mathrm{LVH}$ is positively correlated with PTH levels, particularly in patients with significant secondary hyperparathyroidism. However, this correlation does not hold true for patients with intermediate or low PTH levels. These findings were unchanged after multiple regression adjustment for other parameters involved in LVH. Interestingly, intermediate PTH levels are considered adequate for the bone remodeling processes in uremic patients (13).

Our results agree with those of Stack and Saran (14) who reported that PTH levels above $157 \mathrm{pg} / \mathrm{ml}$ correlated independently with the development of LVH. Nevertheless, contradictory findings about the role of secondary hyperparathyroidism in cardiac changes have been reported in chronic uremic patients. London et al. (6) presented contradictory results concerning the correlation between PTH levels and LVM index, describing a significant negative association. The reason for this discrepancy is not clear, but may be related in part to some methodological aspects. Firstly, PTH values were relatively higher in our patients with great variability in the group of more severe hyperparathyroidism. Secondly, London et al. (6) used a PTH radioimmunoassay tech- nique detecting the terminal C-fragment. This technique measures predominantly inactive PTH metabolites whose excretion is reduced in renal failure (15). These metabolites have biological effects on target tissues including the heart that differ from those of intact PTH.

Anemia is considered to be an important factor in the pathogenesis of LVH, contributing to increased cardiovascular mortality in dialysis patients (16). In the overall group, we observed that hemoglobin was negatively associated with LVM index. However, in multivariate analysis, the correlation of PTH with LVM index was independent of anemia and several other potential confounding factors. Moreover, in patients on dialysis, the presence of anemia is combined with chronic volume overload and it has been shown that the use of human recombinant erythropoietin can attenuate LVH by correcting anemia (17).

High blood pressure is also strongly associated with LVH development $(16,18,19)$. Foley et al. (18) showed that hypertension in chronic dialysis is associated with concentric hypertrophy of the left ventricle. Hypertensive hemodialysis patients have LVM indices that are significantly higher than their normotensive counterparts. However, LVM indices are similar to those of non-uremic hypertensive patients, demonstrating that inadequate blood pressure control is an important factor for the development of $\mathrm{LVH}$ (20). In order to avoid such an interaction, we selected for the present study only normotensive or well-controlled hypertensive patients. Among the 19 patients using antihypertensive medications, 14 were taking 1 drug and 5 were taking two drugs for blood pressure control (data not shown). Systolic blood pressure, which was included in the multivariate analysis, did not affect the association of PHT with LVH.

In the past years, there has been compelling evidence that the cardiovascular system is a major target of PTH action, suggesting 
that its chronic elevation in ESRD patients adversely affects myocardial metabolism and function (4). LVH in uremic patients is not only characterized by an increased myocardial fiber mass but also by myocardial interstitial fibrosis (21). The mechanisms by which PTH induces LVH have not been completely elucidated. Studies have shown increased cytosolic calcium and/or protein kinase $\mathrm{C}$ activation. Expression of cardiac proto-oncogene may be enhanced, which in turn may lead to altered expression of several genes involved on cardiac structure and action and ultimately stimulate the translation of contractile and non-contractile cardiac muscle proteins leading to LVH (22). These studies also suggest that PTH has a permissive role for fibroblast activation and myocardial fibrosis. Thus, it has been observed that elevated PTH levels in ESRD cause irreversible interstitial fibrosis with collagen deposition (23). Following parathyroidectomy in animals with chronic renal failure, a reduction of collagen deposition in the myocardium is consistently observed (22). Interactions between PTH levels and cardiac abnormalities specifically related to LVH and left ventricular diastolic dysfunction were shown in patients with primary hyperparathyroidism as well (24-26). Such abnormalities were independent of plasma calcium levels and hypertension and also regressed following parathyroid mass re- duction (24-27).

Since numerous factors are involved in the genesis of LVH in chronic hemodialysis patients, one should not expect that isolated interventions on specific targets will lead to complete correction of this condition. Control of these factors, however, is vital and may significantly reduce $\mathrm{LVH}$ related to ESRD. This can be observed in patients after successful renal transplantation (28). Moreover, it has been demonstrated that parathyroidectomy exerts a significant role in decreasing LVM index among dialysis patients with tertiary hyperparathyroidism (29).

Although several comorbidities associated with chronic renal failure may contribute to the development of $\mathrm{LVH}$, the findings of the present study suggest that secondary hyperparathyroidism plays an important and independent role in this process. Based on the current state of our knowledge, patients with early renal failure should have their PTH levels monitored and kept within adequate levels, by the judicious use of routine interventions, including dietary protein restriction, the prescription of phosphate binders and the proper use of vitamin D analogs. It also seems adequate to periodically evaluate left ventricular morphological parameters and cardiac geometry by echocardiography, especially in those patients with multiple risk factors for LVH development.

\section{References}

1. Parfrey PS, Harnett JD \& Barre PE (1991). The natural history of myocardial disease in dialysis patients. Journal of the American Society of Nephrology, 2: 2-12.

2. Foley RN, Parfrey PS, Harnett JD et al. (1995). Clinical and echocardiographic disease in patients starting end-stage renal disease therapy. Kidney International, 47: 186-192.

3. Harnett JD, Parfrey PS, Griffiths SM et al. (1988). Left ventricular hypertrophy in end-stage renal disease. Nephron, 48: 107-115.

4. Massry SG \& Smogorzewski M (1996). The heart in uremia. Seminars in Nephrology, 16: 214-221.

5. Foley RN \& Parfrey PS (1997). Cardiac disease in chronic uremia: clinical outcome and risk factors. Advances in Renal Replacement Therapy, 4: 234-248.
6. London GM, De Vernejoul MC, Fabiani F et al. (1997). Secondary hyperparathyroidism and cardiac hypertrophy in hemodialysis patients. Kidney International, 32: 900-907.

7. Amann K \& Ritz E (1997). Cardiac disease in chronic uremia: pathophysiology. Advances in Renal Replacement Therapy, 4: 212224.

8. Avram MM, Sreedhara R, Avram DK et al. (1996). Enrollment parathyroid hormone level is a new marker of survival in hemodialysis and peritoneal dialysis therapy for uremia. American Journal of Kidney Diseases, 28: 924-930.

9. Strozecki P, Adamowicz A, Nartowicz E et al. (2001). Parathormone, calcium, phosphorus and left ventricular structure and function in normotensive hemodialysis patients. Renal Failure, 23: 115-126. 
10. Devereux RB, Alonso DR, Lutas EM et al. (1986). Echocardiographic assessment of left ventricular hypertrophy: comparison to necropsy findings. American Journal of Cardiology, 57: 450-458.

11. Levy D, Savage DD, Garrison RJ et al. (1987). Echocardiographic criteria for left ventricular hypertrophy: the Framingham Heart Study. American Journal of Cardiology, 59: 956-960.

12. Moss DW \& Whitby LG (1975). A simplified heat-inativation curves of alkaline phosphatase isoenzymes in serum. Clinica Chimica Acta, 61: 63-71.

13. Rostand SG \& Drüeke TB (1999). Parathyroid hormone, vitamin D, and cardiovascular disease in chronic renal failure. Kidney International, 56: 383-392.

14. Stack AG \& Saran R (2002). Clinical correlates and mortality impact of left ventricular hypertrophy among new ESRD patients in the United States. American Journal of Kidney Diseases, 40: 12021210.

15. Endres DB, Villanueva R, Sharp Jr CF et al. (1989). Measurements of parathyroid hormone. Endocrinology and Metabolism Clinics of North America, 18: 611-629.

16. Harnett JD, Kent GM, Barre PE et al. (1994). Risk factors for the development of left ventricular hypertrophy in a prospectively followed cohort of dialysis patients. Journal of the American Society of Nephrology, 4: 1486-1490.

17. MacDougall IC, Lewis NP, Saunders MJ et al. (1990). Long-term cardiorespiratory effects on amelioration of renal anaemia by erythropoetin. Lancet, 335: 489-493.

18. Foley RN, Parfrey PS, Harnett JD et al. (1996). Impact of hypertension on cardiomyopathy, morbidity and mortality in end-stage renal disease. Kidney International, 49: 1379-1385.

19. London GM (2002). Left ventricular alterations and end stage renal disease. Nephrology, Dialysis, Transplantation, 18 (Suppl 1): 29-36.

20. Cuspidi C, Lonati L, Sampieri L et al. (2000). Impact of blood pressure control on prevalence of left ventricular hypertrophy in treated hypertensive patients. Cardiology, 93: 149-154.

21. Mall G, Huther W, Schneider J et al. (1990). Diffuse intermyocardiocytic fibrosis in uraemic patients. Nephrology, Dialysis, Transplantation, 5: 39-44.

22. Mall G, Rambausek M, Neumeister A et al. (1988). Myocardial interstitial fibrosis in experimental uremia - implication for cardiac compliance. Kidney International, 33: 804-811.

23. Amann K, Ritz E, Wiest G et al. (1994). A role of parathyroid hormone for the activation of cardiac fibroblasts in uremia. Journal of the American Society of Nephrology, 4: 1814-1819.

24. Nappi S, Saha H, Virtanen V et al. (2000). Left ventricular structure and function in primary hyperparathyroidism before and after parathyroidectomy. Cardiology, 93: 229-233.

25. Saleh FN, Schirmer H, Sundsfjord J et al. (2003). Parathyroid hormone and left ventricular hypertrophy. European Heart Journal, 24 2054-2060.

26. Andersson P, Rydberg E \& Willenheimer R (2004). Primary hyperparathyroidism and heart disease - a review. European Heart Journal, 25: 1776-1787.

27. Dominiczak AF, Lyall F, Morton JJ et al. (1990). Blood pressure, left ventricular mass and intracellular calcium in primary hyperparathyroidism. Clinical Science, 78: 127-132.

28. Ferreira SR, Moises VA, Tavares A et al. (2002). Cardiovascular effects of successful renal transplantation: a 1-year sequential study of left ventricular morphology and function, and 24-hour blood pressure profile. Transplantation, 74: 1580-1587.

29. Chow KM, Szeto CC, Kum LC et al. (2003). Improved health-related quality of life and left ventricular hypertrophy among dialysis patients treated with parathyroidectomy. Journal of Nephrology, 16: 878-885. 